Paulo Ladeira de Carvalho, professor de direito penal na Faculdade de Direito Benett, procurador do Instituto Nacional de Previdência Social - INPS.

Paulo Ladeira de Carvalho

\title{
O sistema de penas na reforma penal
}

Retroagindo no tempo, vamos encontrar a primeira legislação penal que efetivamente vigorou no Brasil, ou seja, o Livro $V$ das ordenações filipinas (1603). Pode-se dizer que a severidade das penas não estava acorde com os atos praticados e sua repercussão no meio social. Feiticeiros, adivinhos, benzedores de animais eram reprimidos com energia excessiva; as penas eram absolutamente desproporcionadas. Isso levou o conselheiro Baptista Pereira a afirmar que o referido Livro $V$ "era um misto de beatice e crueldade".

Com a Independência, surgiu a Constituição de 1824 que proclamou veemente repulsa às Ordenações filipinas, determinando no art. 179, n: 18, a "organização de um Código criminal fundado nas sólidas bases da justiça e da equidade". Determinou a abolição dos açoites, da tortura, da marca de ferro quente, a personalização da pena e a abolição do confisco.

Em seu art. 179, n. 21, dispôs que "as cadeias serão seguras, limpas e bem arejadas, havendo diversas casas para a separação dos réus, conforme suas circunstâncias e natureza dos seus crimes".

Era essa a primeira manifestação da legislação brasileira sobre as prisões, certamente sob o influxo dos postulados da Revolução Francesa, da obra de Baccaria e, em geral, das concepções do sécuło de Voltaire. No título VIII (Garantias dos direitos civis e políticos dos cidadãos brasileiros), constatamos semelhanças profundas com a Declaração dos direitos do homem e do cidadão.

Em 1830 sobreveio o Código criminal do Império, com seus 313 artigos que, segundo afirmou o professor argentino Ladisláu Thot, em conferência proferida neste Instituto em 3 de julho de 1930 , exerceu forte influência sobre as legislações espanhola e latino-americana, tendo como aspecto distintivo ter sido na América Latina o primeiro Código efetivamente nacional e próprio.

As penas nele previstas (capítulo I, título II) eram a morte, as galés perpétuas, a prisão com trabalho, prisão simples, o banimento, o degredo, o desterro, a suspensão do emprego, a perda do emprego e os açoites em escravos.

Seguiu-se-lhe o Código penal de 1890 que, segundo seus comentadores, teve um mal início, pois que se chocava freqüentemente com a Constituição republicana de 1891, gerando uma caudal de legislação complementar tão impressionante que, em 1932, foi substituido pela Consolidação das leis penais.

Suas penas eram a prisão celular, a reclusão, a prisão com trabalho obrigatório e a prisão disciplinar para os menores de 21 anos. Além dessas, permaneciam o banimento, a interdição e a multa.

Em 1932 - como se disse - surge a Consolidação das leis penais, obra do desembargador Vicente Piragibe, aprovada pelo decreto n: 22.213, de 14 de dezembro de 1932, e que foi elaborada em virtude de o Código penal de 1890 ter sofrido tantas modificações que já dificultavam não só o conhecimento como a aplicação da lei penal e, não sendo lícito invocar a ignorância do direito, deviam as leis estar ao alcance de todos.

Deixados de lado os inúmeros anteprojetos e estudos oferecidos durante o princípio do século, chegamos ao Código de 1940 que, no seu artigo 28, adota como penas principais a reclusão, a detenção e a multa, além das penas accessórias de perda de 
função pública, interdições de direito e a publicação da sentença.

E toda a legislação complementar e especial segue o mesmo figurino, ficando absolutamente claro que "a prisão é o centro de gravidade dos esquemas políticos-criminais", no dizer autorizado de René Ariel Dotti.

Em 1963 surge o anteprojeto Nelson Hungria que, após tumultuada revisão por várias comissões, recebe redação definitiva do profesor Benjamin Moraes Filho e é decretado pela Junta Militar que governava o país - isto em 21 de outubro de 1969. O decreto-lei n: 1004 iniciou então tortuoso caminho em busca de sua efetiva vigência que, afinal, não veio. Sofreu inclusive, profundas modificações pela lei n. 6.016, de 31 de dezembro de 1973; protelada sua vigência por várias vezes, acabou sendo revogado pela lei n. 6.578, de 11 de outubro de 1978.

A essa altura, já era absolutamente claro o aumento vertiginoso da criminalidade e, conseqüentemente, surgia como um pesadelo o problema da superlotação das prisõeš - policiais e penitenciárias. Ainda assim, não se podia notar qualquer posição definida em prol da melhoria dessas condições aflitivas. Vigorava ainda a presunção de que a solução residia na construção de novos estabelecimentos penais.

É justamente nessa fase, segundo informa a professora Armida Bergamini Miotto, em trabalho publicado em 1977 na Revista da Informação Legislativa $n$. 54 , que os estudiosos brasileiros, criminologistas, penitenciaristas e sociólogos se engajam abertamente numa reação contra o uso desmedido da pena privativa da liberdade, assim, como do ponto de vista processual, do instituto da prisão preventiva.

E na gestão do ministro da Justiça professor Alfredo Buzaid, já decidido o governo a revogar o decreto-lei n. 1004/69, lançou-se à tarefa de procurar minimizar o problema, encetando estudos que, certamente, são os germes da lei n: 6.416, de 24 de maio de 1977. De todos esses trabalhos, o que mais concorreu para a concretização de novas legislativas foi o relatório da Comissão Parlamentar de Inquérito da Câmara dos Deputados, destinada ao levantamento da situação penitenciária do país, da qual foi relator o então deputado Ibrahim Abi-Ackel. Esse relatório foi aprovado pelo projeto de resolução n. 70, de 11 de março de 1976; dispunha ele, em suas conclusões, o seguinte: "Torna-se mister a elaboração de um novo sistema de penas, com substitutivos à pena de prisão, nos casos adequados, tais como:

- ampliação do instituto da suspensão con- dicional da pena, de forma a ensejar sua aplicação com maior largueza;

- prescrição da reincidência dentro do prazo de cinco anos, uma vez cumprida a pena;

- repetição da suspensão condicional da pena, confiado ao juiz o arbítrio para concedê-la nos casos em que concença da inexistência de periculosidade;

- ampliação do elenco de casos de substituição da pena de reclusão ou multa;

- adoção da pena de prisão domiciliar, restritiva dos direitos de locomoção do imputado;

- adoção da prisão albergue domiciliar, como semente do probation (fiscalização);

- interdição de direito, dentro os quais a suspensão ou a cassação do direito ao exercício de profissão;

- suspensão ou cassação da carteira de habilitação para dirigir veículo".

De todo esse trabalho do Ministério da Justiça resultou anteprojeto que se transformou na lei $n$. 6.416 , de 24 de maio de 1977, chamada de A reforma do sistema de penas e que, na realidade, veio humanizar o cumprimento das penas privativas de liberdade. Seu objetivo, segundo a exposição de motivos; foi o de corrigir as conseqüências dramáticas decorrentes da superlotação dos estabelcimentos prisionais.

Sem ferir o sistema de legislação penal em vigor, procurou-se uma solução condizente com a tendência moderna de reservar as penas privativas da liberdade somente para os autores de delitos mais graves e para aqueles condenados cujas características de personalidade assim o exigem. De igual modo procedeu-se, no plano processual, quanto à prisão provisória - a ser utilizada somente quando e na medida em que for necessária aos interesses da justiça, da segurança social e da ordem pública. Adotou essa nova legislação a ampliação da suspensão condicional da pena e do livramento condicional, fazendo desaparecer o hiato então existente entre o máximo de pena relativo à suspensão e o mínimo para o livramento. Eliminou-se a distinção entre reincidência genérica e específica, prevendo-se expressamente a sua prescrição.

Paralelamente a toda essa atividade, merece registro especial o anteprojeto elaborado, em 1971. por um grupo de penalistas de São Paulo, liderados pelo professor Manoel Pedro Pimentel, trabalho esse derivado de uma tese apresentada ao II. Congresso Paulista do Ministério Público pelos Drs. Francisco Papaterra Limongi Neto e Antônio Carlos Penteado de Moraes. 
Esse anteprojeto foi exposto na reunião dos secretários de justiça, realizada nesse mesmo ano de 1971, em Nova Friburgo, e afirmava que o "Código penal de 1969 não espelhava corretamente a questão das penas, nem ao menos o equacionava racionalmente", acrescentando que deveriam ser promovidas modificações urgentes no Código penal de 1940, visando à alteração da filosofia penal vigente e que "a nova filosofia radicava-se no entendimento de que a pena de prisão deveria ser reservada para os criminosos portadores de periculosidade. Era a idéia que dominara o Congresso realizado pela Organização das Nações Unidas, em 1970, na cidade de Kioto. Era preciso estabelecer um divisor de águas, para aferir quem deveria ficar preso e quem poderia ficar solto".

Um dos méritos desse anteprojeto era o de já colocar a pena de interdição de direitos como pena principal. Como o Ministério da Justiça não Ihe deu a esperada atenção, o anteprojeto foi adotado pelo então senador Franco Montoro, que o apresentou ao Senado Federal sob a forma de projeto de lei, delegando-se as funções de relator ao saudoso senador Accioly Filho. Lá esse projeto foi atropelado pelo projeto n. 1.457 , que veio a se converter na lei n. 6.016/73, modificadora do Código de 1969 (decreto-lei n. 1004).

Como bem se pode ver desse rápido escorço histórico, toda a problemática da pena reside na chamada 'crise da prisão' e na dúvida reinante sobre os reais efeitos da pena de multa; principalmente na primeira. Afirma-se mesmo que a prisão não só deixa de cumprir sua tarefa ressocializante como até mesmo colabora de maneira nítida para a reincidência, já que é reiteradamente considerada fator criminógeno. As referências nesse sentido, na literatura nacional e estrangeira, são inúmeras. Apenas como ilustração, citaremos a seguir algumas das mais contundentes.

O professor Alípio Silveira, em sua obra Teoria e prática de prisão albergue (São Paulo, 1972), pergunta: "até que ponto influi a prisão como fator criminogênico, como escola oficial do crime?"; e responde: "um notável criminólogo, o professor Edmond Locard, considera a prisão como o fator criminogênico por excelência. Eis suas palavras: 'Não existem verdadeiros profissionais do crime senão após sua passagem por estabelecimentos penitenciários. É somente depois de ser detido e condenado por um pequeno furto, por uma rixa, por resistência a agentes de polícia, que o homem se torna criminoso habitual'.

Magalhães Drumond assim define prisão: "Uns horríveis depósitos de desgraçados, enxovias sem luz, sem ar, sem asseio, que podem servir e têm, de certo, servido - para brutalizar ainda mais e para matar por morte lenta os desafortunados que a elas vão ter (Aspectos do problema penal brasileiro, p. 13).

Na literatura alienígena a opinião é a mesma. Os criminólogos americanos Barnes e Teeters, em Novos horizontes em criminologia - obra responsável por uma verdadeira revolução no sistema penitenciário norte-americano - afirmam que "o aspecto mais deplorável das prisões modernas não é tanto a crueldade, mas a desintegração da personalidade do prisioneiro. Quase tudo que pode contribuir a destruir e a desmoralizar a personalidade humana encontra-se na prisão de hoje e nos métodos contemporâneos da administração penal".

As investidas contra a prisão se sucedem, partidas de todos os especialistas que se defrontam com o problema, como se constituíssem num aplauiso geral à célebre frase de Oscar Wilde, em A balada do cárcere, quando diz que "as prisões foram construídas com os tijolos da infâmia". É nesse clima que surge o anteprojeto de 1981. Pela portaria n: 1043, de 27 de novembro de 1980, do senhor ministro da Justiça, foi instituída uma comissão presidida pelo professor Francisco de Assis Toledo e composta dos professores Serrano Neves, Ricardo Antunes Andreucci, Miguel Reale Jr., Hélio Fonseca, Rogério Lauria Tucci e René Ariel Dotti, para elaborar anteprojeto de lei modificadora da parte geral do Código penal.

O título $V$, que trata das penas em espécies, está assim estruturado:

\section{Das penas}

\section{Capítulo I - Das espécies de pena} Penas

Art. 32 - As penas são: I - privativas de liberdade. II - restritivas de direitos; III patrimoniais.

\section{Seção I - Das penas privativas de liberdade}

\section{Reclusão e detenção}

Art. 33 - A pena de reclusão deve ser cumprida em regime fechado, semi-aberto ou aberto e a de detenção em regime semi-aberto ou aberto.

$\S 11^{\circ}$ - Considera-se: 1 - regime fechado a execução da pena em estabelecimento de segurança máxima ou média;

II - regime semi-aberto a execução de pena em colônia agrícola, industrial ou em estabelecimento similar; III - regime aberto a execução da pena em caso de albergado ou estabelecimento similar.

\section{$\S 2$ ? - As penas privativas de liberdade deve-}


rão ser executadas em forma progressiva, segundo o mérito do condenado, observados os seguintes critérios e ressalvadas as revogações e retornos: I o condenado a pena superior a oito anos deverá começar a cumprí-la em regime fechado; II - o condenado, cuja pena seja superior a quatro anos e não exceda a oito, poderá desde o princípio cumpri-la em regime semi-aberto; III - o condenado, cuja pena seja inferior a quatro anos, poderá desde o início cumpri-la em regime aberto.

\section{Regras do regime fechado}

Art. 34 - O condenado deverá ser submetido, no início do cumprimento da pena em regime fechado, a exame criminológico, para fins de classificação e individualização da execução;

$\S 10^{\circ}-$ o condenado fica sujeito a trabalho no período diurno e a isolamento durante o repouso noturno;

$\S 2$. $^{\circ}$ - o trabalho será em comum dentro do estabelecimento, na conformidade das aptidões ou ocupações anteriores do condenado, desde que compatíveis com os objetivos da pena;

$\S 3^{\circ}$. - o trabalho externo é admissivel, no regime fechado, em serviços ou obras públicas, desde que tomadas as cautelas contra fuga e em favor da disciplina.

\section{Regras do regime semi-aberto}

Art. 35 - O condenado poderá ser submetido, no início do cumprimento da pena, em regime semi-aberto, a exame criminológico, para fins de classificação e individualização da execução;

$\S 1^{\circ}$ - o condenado fica sujeito a trabalho em comum durante o período diurno, em colônia agrícola, industrial ou estabelecimento similar;

$\S 2^{\circ}$. - o trabalho externo é admissivel, bem como freqüência a cursos supletivos profissionalizantes, de instrução de segundo grau ou superior.

\section{Regras do regime aberto}

Art. 36 - 0 regime aberto baseia-se na autodisciplina e senso de responsabilidade do condenado;

$\S 10$ - o condenado deverá, fora do estabelecimento e sem vigilância, trabalhar, freqüentar curso ou exercer outra atividade autorizada, permanecendo recolhido durante o período noturno e nos dias de folga;

$\S 2$. - o condenado será transferido do regime aberto, se praticar outro crime, se frustrar os fins da execução, ou se não pagar, injustificadamente, pena patrimonial cumulativamente aplicada.

\section{Regime especial}

Art. 37 - As mulheres cumprem pena em estabelecimento próprio, observando-se os deveres e direitos inerentes a sua condição pessoal, bem como, no que couber, o disposto neste capítulo.

\section{Direitos do preso}

Art. 38 - O preso conserva todos os direitos não atingidos pela perda da liberdade, impondo-se a todas as autoridades o respeito a sua integridade física e moral.

\section{Trabalho do preso}

Art. 39 - O trabalho do preso será sempre remunerado, sendo-lhe garantidos os benefícios da Previdência Social.

\section{Legislação especial}

Art. 40 - A legislação especial regulará a matéria prevista nos artigos 38 e 39, bem como especificará os deveres e direitos do preso, os critérios para revogação e transferência dos regimes, estabelecerá as infrações disciplinares e correspondentes sanções.

\section{Superveniência de doença mental}

Art. 41 - O condenado a que sobrevém doença mental deve ser recolhido a manicômio judiciário ou, à falta, a outro estabelecimento adequado, onde lhe seja assegurada a custódia.

Detração

Art. 42 - Computam-se, na pena privativa da liberdade, o tempo de prisão provisória, no Brasil ou no estrangeiro, o de prisão administrativa e o de internação em hospital ou manicômio.

Parágrafo único - Computa-se, igualmente, o tempo indevidamente cumprido, relativo à condenação por crime posterior, invalidade em decisão judicial irrecorrível.

\section{Seção II - Das penas restritivas de direitos}

Penas restritivas de direitos

Art. 43 - As penas restritivas de direito são: I - prestação de serviços à comunidade; II - interdição temporária de direitos; III - aprendizado compulsório.

\section{Requisitos das penas restritivas de direitos}

Art. 44 - As penas restritivas de direitos são autônomas e podem ser aplicadas desde que: I a pena máxima privativa de liberdade, cominada ao crime, não seja superior a três anos; II - o réu não seja reincidente em crime doloso, observado o disposto no artigo 64; III - as circunstâncias e os motivos determinantes, os antecedentes, a personali- 
dade e conduta social do condenado indiquem que essas modalidades de pena sejam necessárias e suficientes.

Critérios de aplicação das penas restritivas de direitos Art. 45 - Na aplicação das penas restritivas de direitos serão observados os seguintes critérios: I - nos crimes, cuja pena máxima privativa de liberdade seja inferior a um ano, poderá ser aplicada isoladamente uma única pena, salvo o disposto no art. 48, parágrafo único; II - nos crimes, cuja pena máxima privativa de liberdade seja igual ou superior a um ano e não exceda a três anos, poderão ser aplicadas duas penas a serem cumpridas simultaneamente.

\section{Conversão das penas restritivas de direitos}

Parágrafo único - $O$ descumprimento, injustificado, a qualquer momento, de penas restritivas de direitos, aplicadas isolada ou cumulativamente, determina sua conversão em pena privativa de liberdade, pelo tempo de pena mínima cominada ao crime

\section{Prestação de serviços à comunidade}

Art. 46 - A prestação de serviços à comunidade consiste na atribuição ao condenado de trabalho gratuito junto a entidades assistenciais, hospitais, escolas, orfanatos e outros estabelecimentos congêneres ou em programa comunitários.

Parágrafo único - As tarefas serão atribuídas conforme as aptidões do condenado, devendo ser cumpridas aos sábados, domingos e feriados, ou nos dias úteis, por duas horas, durante o tempo fixado.

Interdição temporária de direitos

Art. 47 - As penas de interdição temporária de direitos são: I - proibição do exercício de cargo, função ou atividade pública, bem como de mandato eletivo; II - proibição do exercício de profissão ou atividade que dependam de hábilitação especial, de licença ou autorização do poder público; III - Cassação de licença de habilitação para dirigir veículos.

\section{Aprendizado compulsório}

Art. 48 - O aprendizado compulsório consiste na freqüência a curso ou ciclo de palestras, no qual o condenado por crime culposo venha a adquirir conhecimentos necessários a evitar a ocorrência de nova infração e a estimular o dever social de cuidado.

Parágrafo único - A pena de aprendizado compulsório poderá ser aplicada isoladamente nos crimes culposos cuja pena máxima cominada não seja superior a um ano.
Seção III - Das penas patrimoniais

\section{Multa penitenciária}

Art. 49 - A pena de multa penitenciária consiste no pagamento ao fundo penitenciário da quantia fixada na sentença e calculada em dias-multa. Será, no nínimo, de dez e, no máximo, de trezentos dias-multa.

Parágrafo único - $\mathrm{O}$ valor do dia-multa será fixado pelo juiz, não podendo ser inferior a um trigésimo do maior salário mínimo mensal vigente ao tempo do fato, nem superior a cinco vezes esses salário.

\section{Pagamento da multa}

Art. 50 - A multa deve ser paga dentro de dez dias depois de transitada em julgado a sentença. A requerimento do condenado e conforme as circunstâncias, o juiz pode permitir que o pagamento se realize em parcelas mensais.

$\S 11^{\circ}-$ A cobrança da multa pode efetuar-se mediante desconto no vencimento ou salário do condenado se imposta isoladamente, se aplicada cumulativamente com pena restritiva de direitos ou quando concedida a suspensão condicional da pena.

§ 2.- O desconto não deve incidir sobre os recursos indispensáveis ao sustento do condenado e de sua família.

\section{Conversão da multa e revogação}

Art. 51 - A multa converte-se em pena de detenção, quando o condenado solvente deixa de pagá-la ou frustra a sua execução.

Modo de conversão

$\S 11^{\circ}-$ Na conversão, a cada dia-multa corresponderá um dia de detenção, não podendo esta ser superior a um ano.

\section{Revogação da conversão}

$\S 2^{\circ}$ - A conversão fica sem efeito se, a qualquer tempo, é paga a multa.

\section{Suspensão da execução}

Art. 52 - É suspensa a execução da pena de multa, se sobrevém ao condenado doença mental.

\section{Multa reparatória}

Art. 53 - A pena de multa reparatória consiste no pagamento, mediante depósito judicial, em favor da vítima, ou seus sucessores, de quantia calculada com base no disposto no artigo 49 e seu parágrafo, sempre que houver prejuízo material resultante do crime.

§ 1․ - A multa reparatória não poderá ser su- 
perior ao valor do prejuízo demonstrado no processo.

$\S 2^{\circ}$ - Aplica-se à multa reparatória o disposto nos artigos 49, segundo parte, a 52 .

$\S 3^{\circ}$ - - Na indenização civil do dano, o valor da multa reparatória será descontado.

Aplicação autônoma das multas

Art. 54 - A pena de detenção não superior a seis meses pode ser substituída pela de multa, observados os incisos II e III do artigo 44.

$\S 10^{\circ}$ - As multas penitenciárias e reparatória poderão ser cumuladas tão-só quando forem as únicas penas aplicadas.

$\S 22^{\circ}$ - No pagamento ou execução das penas patrimoniais, a multa reparatória prefere à multa penitenciária.

§ $3^{\circ}$ - Uma única pena de multa poderá ser cumulada com pena privativa de liberdade, ou restritiva de direitos."

Este anteprojeto foi intensamente debatido pelos estudiosos, inclusive em memorável sessão deste Instituto, realizada à 22 de abril de 1981, e da qual participaram os professores Virgílio Luiz Donnici, Heleno Cláudio Fragoso, Técio Lins e Silva, e José Frederico Marques, e os doutores José Danir Siqueira do Nascimento, Antônio Carlos da Gama Barandier, Laércio da Costa Pellegrino, Sérgio Ferraz e Samuel Buzaglo.

O professor Heleno Fragoso, iniciando o debate, afirmou pessoalmente com relação ao sistema de penas "que o projeto nessa parte está bem inspirado, no sentido de penas alternativas da pena de privação da liberdade". A respeito da multa reparatória, afirmou expressamente achar que ela não é multa. Com relação às outras penas, disse que a do aprendizado compulsório não tem seriedade e que a do trabalho comunitário pode ser prevista - embora com reservas - pois que muitos condenados preferem a prisão tradicional, a cumprir essa pena de trabalho comunitário.

Nessa ocasião afirmamos, sobre o sistema de penas, que não há mais razão para a dicotomia entre reclusão e detenção e que seria mais lógico, como o anteprojeto apresentado no Senado pelo então senador Franco Montoro, adotar-se como privação da liberdade a pena única de prisão, além das interdições de direito e da multa. Quanto a esta acompanhei o ponto de vista do professor Heleno Fragoso de que, como está disciplinada, só tem validade como multa criminal, nunca como reparatória, pois esta nada mais é do que um ressarcimento do dano. Além disso, está ela mal disciplinada porque não estatui o modo de apuração do seu valor. Na ocasião aludimos a um anteprojeto de lei sobre delitos de trânsito, de cuja elaboração participamos e que chegou a prever a reparação do dano no juízo criminal, com disciplina minudente para a fixação de seu valor. Essa tentativa foi abondonada em face das sugestões críticas recebidas, em especial as do professor Damásio de Jesus.

No anteprojeto hoje em exame deparamos com a multa reparatória que, no nosso entender, constitui o seu mais grave erro, pois permite a sua conversão em pena privativa da liberdade resultanto, inequivocamente, essa providência numa prisão por dívida - hipótese expressamente vedada pela Constituição federal.

$\mathrm{O}$ anteprojeto em estudo foi alvo também de um exame do Instituto de Ciências Penais do Rio de Janeiro, em três reuniões realizadas a 10, 23 e 27 de abril de 1981, o qual, pronunciando-se sobre o título cinco, concluiu: "Ao ver do Instituto, aqui residem as mais louváveis e progressistas inovações do anteprojeto, representadas por uma clara opção político-criminal em favor de substitutivos da pena privativa de liberdade, e de uma intervenção reeducadora e tutelar do sistema penal. Decidiu-se adotar as conclusões do grupo de trabalho instituído pela Vara de Execuções Criminais do Estado do Rio de Janeiro, que foram todavia objeto de discussão conjunta. Veja-se o documento anexo ao presente"

O grupo de trabalho instituído na Vara de Execuções Criminais, já referido, e que teve como relator o advogado José Mauro Couto de Assis, teceu em seu parecer várias sugestões, quase todas relacionadas com a redação do título cinco, não sem antes ressaltar que, genericamente, as inovações correspondem aos anseios da mais atualizada doutrina penal, não obstante manter a anacrônica distinção no tocante às penas privativas de liberdade - dispositivo que só poderia encontrar amparo duvidoso na existência de ritos processuais diversos e certos benefícios ou incidentes na execução penal (EStes trabalhos estão publicados na Revista de Direito Penal, número 31, de 1981.).

$\mathrm{O}$ anteprojeto foi ainda examinado no Congresso Mundial do Direito que se reuniu em São Paulo, de 16 a 21 de agosto de 1981 - em virtude de tese apresentada pelo Dr. Laércio Pellegrino, sob o título Algumas inovações da nova legislação penal brasileira - no qual se afirma "merecer muito mais elogios, principalmente pelo seu incentivo humanista, liberal no seu todo, atendendo à nossa realidade no seu objetivo social". 